\title{
Intra-community implications of implementing multiple tsunami-evacuation zones in Alameda, California
}

\author{
Jeff Peters $^{1} \cdot$ Nathan Wood $^{2} \cdot$ Rick Wilson $^{3} \cdot$ Kevin Miller $^{4}$
}

Received: 16 March 2016/Accepted: 13 July 2016/Published online: 19 July 2016

(C) The Author(s) 2016. This article is published with open access at Springerlink.com

\begin{abstract}
Tsunami-evacuation planning in coastal communities is typically based on maximum evacuation zones for a single scenario or a composite of sources; however, this approach may over-evacuate a community and overly disrupt the local economy and strain emergency-service resources. To minimize the potential for future over-evacuations, multiple evacuation zones based on arrival time and inundation extent are being developed for California coastal communities. We use the coastal city of Alameda, California (USA), as a case study to explore population and evacuation implications associated with multiple tsunami-evacuation zones. We use geospatial analyses to estimate the number and type of people in each tsunami-evacuation zone and anisotropic pedestrian evacuation models to estimate pedestrian travel time out of each zone. Results demonstrate that there are tens of thousands of individuals in tsunami-evacuation zones on the two main islands of Alameda, but they will likely have sufficient time to evacuate before wave arrival. Quality of life could be impacted by the high number of government offices, schools, day-care centers, and medical offices in certain evacuation zones and by potentially high population density
\end{abstract}

Jeff Peters

jpeters@usgs.gov

Nathan Wood

nwood@usgs.gov

Rick Wilson

Rick.Wilson@conservation.ca.gov

Kevin Miller

Kevin.Miller@caloes.ca.gov

1 Western Geographic Science Center, United States Geological Survey, 345 Middlefield Road, Menlo Park, CA 94025, USA

2 Western Geographic Science Center, United States Geological Survey, 2130 SW 5th Avenue, Portland, OR 97201, USA

3 California Geological Survey, 801 K Street, MS 12-31, Sacramento, CA 95814, USA

4 California Governor's Office of Emergency Services, 30 Van Ness Ave. Ste. 3300, San Francisco, CA 94102, USA 
at one identified safe area after an evacuation. Multi-jurisdictional evacuation planning may be warranted, given that many at-risk individuals may need to evacuate to neighboring jurisdictions. The use of maximum evacuation zones for local tsunami sources may be warranted given the limited amount of available time to confidently recommend smaller zones which would result in fewer evacuees; however, this approach may also result in over-evacuation and the incorrect perception that successful evacuations are unlikely.

Keywords Tsunami $\cdot$ Evacuation $\cdot$ Exposure $\cdot$ Modeling $\cdot$ Scenario

\section{Introduction}

Tsunami-evacuation planning is challenging in coastal communities due to varying wave arrival times and inundation associated with local and distant tsunami. In many cases, emergency managers will have the difficult job of deciding the magnitude and logistics of an actual evacuation without complete knowledge of the characteristics of an imminent tsunami. They also have the conflicting objectives of encouraging as many people as possible in low-lying areas to evacuate before wave arrival to minimize injuries and loss of life, while also attempting to minimize over-evacuations that may disrupt the local economy, exhaust emergency services, and erode public trust in warning messages (National Research Council 2011; Bernard 2005; Wilson and Miller 2014; Ministry of Civil Defense and Emergency Management 2008).

The range of potential tsunami scenarios in coastal communities has led emergency managers to take different approaches in the development of tsunami-evacuation maps. Some jurisdictions use a maximum tsunami hazard zone from a specific scenario (e.g., Butler 2014; Walsh et al. 2000) or from a composite of multiple sources (e.g., Wilson et al. 2010; California Department of Conservation 2015), both to simplify the public-education message and to maximize the likelihood that they have considered everyone who could be directly impacted by a tsunami. Other jurisdictions, such as the State of Oregon (USA), display two zones on evacuation maps to distinguish local tsunami evacuations where immediate action is necessary if ground shaking is felt (e.g., from a Cascadia subduction zone earthquake in the case of coastal Oregon) and distant tsunami evacuations that will be facilitated by public officials over longer time periods (Priest et al. 2016).

In addition to maximum and local versus distant tsunami-evacuation maps, a third approach to evacuation mapping is the use of multiple evacuation zones that can be implemented during a tsunami event depending on the expected inundation extent and arrival time of the tsunami in specific coastal areas. One example of this approach is tsunami-evacuation maps in New Zealand that have three zones depending on tsunami severity (Ministry of Civil Defense and Emergency Management 2008). Another example is the tsunami-evacuation "playbook" approach being implemented jointly by the California Geological Survey (CGS) and the California Office of Emergency Services (Cal OES). Although evacuations are currently based on a maximum tsunami hazard zone that is a compilation of multiple tsunami sources (Wilson et al. 2010; California Department of Conservation 2015), playbooks for California coastal communities are being developed that contain multiple evacuation zones based on modeled tsunami scenarios, their expected arrival time, and estimated water elevations (e.g., Wilson and Miller 2014). 
Evacuation planning based on tsunami severity during an event is in its infancy in the USA, but detailed and accurate forecast information from the Tsunami Warning Centers provides a good foundation for this approach. To implement real-time evacuations, substantial preparedness and logistical planning still needs to be addressed. For example, California Evacuation Playbook zones are based on discussions with local managers about the characteristics of potential tsunami sources, including extent of inundation and wave arrival time, but are not influenced by the number or type of evacuees for a specific zone. This additional information could help provide community context for the evacuation decision making by emergency managers.

The objective of this paper is to examine the population implications for coastal communities associated with various evacuation zones described within California Tsunami Evacuation Playbooks. This case study provides insight on the development and implementation of multiple tsunami-evacuation zones, not only in California where playbook development is ongoing, but in other coastal jurisdictions throughout the world that are considering similar evacuation maps and procedures. Our case study focuses on the City of Alameda, California, where multiple local and distant tsunami threats exist (Wilson et al. 2010) and previous tsunami exposure studies have estimated substantial differences in population exposure when comparing scenarios versus maximum hazard zones (Wood et al. 2013a; b). First, we use geospatial analysis to estimate the number and type of people in each tsunami-evacuation playbook zone. Second, we model evacuation potential in terms of travel time out of each zone for these at-risk populations using an anisotropic geospatial approach based on path distance algorithms. Third, we compare estimated evacuation travel times to expected tsunami arrival times that determine playbook zone recommendations and discuss the implications of this work on tsunami-evacuation planning. Evacuation travel-time maps and population exposure estimates resulting from this process will help emergency managers appreciate the implications of deciding when to evacuate one zone versus others, as well as target populations in areas of their city that could have challenges reaching safety during future tsunamis.

\section{Study area}

The City of Alameda, California (population 73,063; US Census Bureau 2014a), is a series of islands (Alameda, Bay Farm, and Coast Guard Islands) located along the eastern shore of San Francisco Bay (Fig. 1). Alameda Island contains approximately $80 \%$ of city residents, the majority of commerce, and all government offices (except for US Coast Guard offices on Coast Guard Island). The western side of Alameda Island known as Alameda Point includes the decommissioned Alameda Naval Air Station (NAS), consisting largely of paved runways currently used for special events but are slated for development in the near future (Alameda Point Info 2016). Alameda Island's south shore includes Robert W. Crown Memorial State Beach, docks serving the USS Hornet Aircraft Carrier Museum, and two small recreational marinas. Alameda Island's north shore has several large recreation boating marinas and a ferry terminal dock. Coast Guard Island is an artificial island located off of the northeast shore of Alameda Island, is connected via a bridge to Oakland, and contains several US Coast Guard facilities. Bay Farm Island is actually a peninsula and is primarily developed with single-family residences and high occupancy apartment complexes, with a large commercial complex on the south side, a ferry terminal 


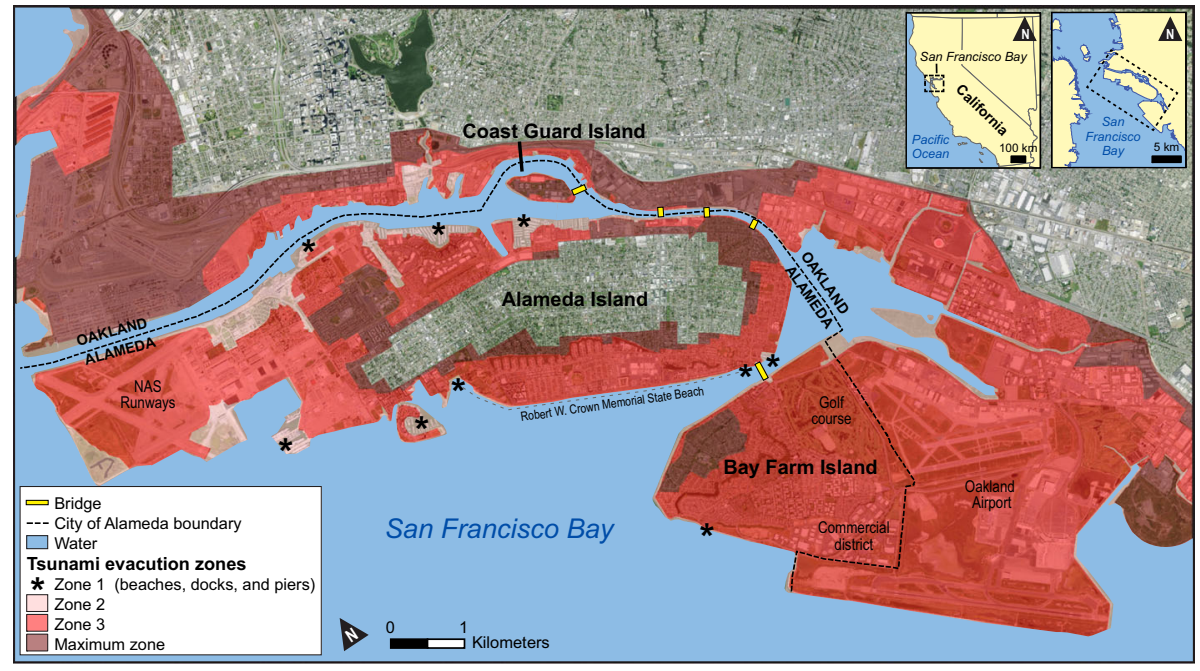

Fig. 1 Map of the City of Alameda (California, USA) various islands and noteworthy locations and features

on the west side, and a golf course on the east side of the island. Oakland International Airport is east of Bay Farm Island and separates it from the mainland (Fig. 1).

The City of Alameda and other California coastal communities are susceptible to tsunamis generated by both local and distant earthquake sources (Wilson and Miller 2014). A maximum tsunami inundation zone derived from composites of potential distant and local sources has been mapped for all coastal California jurisdictions (Wilson et al. 2010; California Department of Conservation 2015). Wood et al. (2013a) estimate that there are approximately 39,515 Alameda residents in the maximum tsunami hazard zone, which is the highest residential exposure for one city to tsunami hazards in California. Another report that summarizes population exposure for a tsunami scenario associated with an Aleutian-Alaska subduction zone earthquake includes estimates of only 3332 Alameda residents in that specific zone (Wood et al. 2013b). This difference in population exposure highlights the potential issue of over-evacuations when maximum hazard zones are used in all evacuation situations, instead of smaller, more accurate zones which may better reflect the actual threat of inundation from a specific event.

\section{Methods}

To examine population implications of various tsunami-evacuation zones in Alameda, we used geographic information system (GIS) software and various geospatial evacuation, demographic, and land cover data to estimate population distributions and model pedestrian evacuation potential movement out of evacuation zones to safe, high ground. We discuss here the various data and methods required to compile such estimates.

\subsection{Tsunami-evacuation playbook zones for Alameda}

To provide options for evacuation planning to emergency planners in California, CGS and Cal OES are working with coastal communities to develop evacuation playbooks that 
include multiple evacuation zones (referred to as phases in Wilson and Miller 2014) based on tsunami scenarios of varying inundation potential (Fig. 1) (Wilson and Miller 2014). Playbook development was motivated by the inconsistency in evacuations statewide during the tsunami "Warning" in California for the 2011 Japan tsunami. The city of Crescent City and several unincorporated communities implemented full evacuations to their Maximum Zones, in accordance with existing local tsunami protocols for almost all California communities that called for Maximum Zone evacuations for all Warning-level tsunamis. However, public-safety officials in many other communities along the California coast did not call for residential evacuations. Decisions not to evacuate were motivated by forecasts from the National Tsunami Warning Center (NTWC) that expected tsunami water elevations along the California coast would be small to moderate in size (1.0-2.5 m) and that tidal conditions during the first several hours of tsunami activity would be relatively low. NTWC representatives discussed these forecasts and any updates during several conference calls with coastal counties and communities after the initial earthquake in Japan. Therefore, while coastal communities were provided the same information regarding imminent tsunami threats, different evacuation decisions were made locally based on individual interpretations and risk tolerance of this information, and not based on any formal decision-making process (Wilson and Miller 2014). The tsunami playbook is an attempt to improve local decision making and standardize response activities for coastal emergency managers by providing recommendations on minimum areas to evacuate based on the size and location of a specific tsunami threat.

The decision as to which playbook zone to evacuate during a tsunami evacuation is ultimately up to the local emergency managers, but the evacuation playbooks include a process to help with this decision. First, communities obtain basic earthquake and tsunami forecast information from the National Tsunami Warning Center, regional National Oceanic and Atmospheric Administration (NOAA) Weather Forecast offices, and/or the State as to the magnitude, source location, and travel time of the tsunami. If the tsunami is triggered by a local or regional source, such as the Cascadia or Alaska subduction zones which have expected arrival times of less than $4 \mathrm{~h}$ to reach Alameda, then a preset, scenario-based evacuation plan is recommended for use. In most cases, an evacuation of the playbook Maximum Zone will likely be implemented for these local or regional events to reduce confusion and limit delays in decision making.

If the expected tsunami wave arrival time is more than $4 \mathrm{~h}$ after initial ground shaking, the secondary playbook evacuation zone plans can be implemented. To help determine which phase evacuation zone to use, the State and NOAA Weather Forecast offices will calculate the expected tsunami flood elevation, referred to as the "FASTER" value that integrates: Forecasted Amplitude (wave height); storm Surge or existing ocean conditions; maximum Tidal height during the first $5 \mathrm{~h}$ of tsunami); forecast Error potential (assumed to be $30 \%$ based on an analysis of 2010-2011 events); and a site-amplified Run-up potential determined from existing modeling, which is unique to each location and is applied if inundation is expected (Wilson and Miller 2014). The State and NOAA then use the resulting FASTER water elevation value to select and recommend the appropriate tsunami playbook evacuation zone for each community. These results are sent to all the communities in real time and are recommended as a "minimum" for response and evacuation.

The City of Alameda has four playbook evacuation zones (1, 2, 3, and Maximum), which are described in greater detail in Wilson and Miller (2015). Areas in evacuation zones closer to the water are included in the larger zones; for example, individuals in Zone 2 would be included in the evacuation when a Zone 3 evacuation is implemented (Fig. 1). Zones can be grouped primarily by wave arrival time, in that Zones 1-3 are encouraged for 
distant tsunamis with wave arrival times greater than $4 \mathrm{~h}$, and the Maximum Zone is encouraged for distant and local tsunamis with arrival times less than $4 \mathrm{~h}$. Distinctions among zones 1-3 are based primarily on expected water elevations using the FASTER methodology. Zone 1 is intended to be used for events with expected FASTER water elevations of less than $1 \mathrm{~m}$ above mean sea level and is descriptive (i.e., no definitive spatial boundary), calling for evacuation of beaches, harbor docks, and piers (stars in Fig. 1). Zone 2 would be recommended for tsunamis with FASTER water elevations of $1.0-1.5 \mathrm{~m}$ and only affects Alameda Island. No Bay Farm Island shoreline is expected to be inundated in a Zone 2 evacuation, although the ferry terminal on Bay Farm Island would be encouraged to evacuate (as it would with a Zone 1 evacuation). Zone 3 relates to FASTER water elevations of 1.5-2.5 m, affecting both Alameda and Bay Farm Islands with areas on both islands for evacuees to seek safety.

As previously mentioned, the Alameda playbook recommends a Maximum Zone evacuation (Fig. 1) for tsunamis that are expected to arrive with less than $4 \mathrm{~h}$ which includes large earthquakes associated with the Cascadia or Alaska subduction zones. Four hours is not considered enough time for emergency managers to assess impending tsunami characteristics, run a FASTER calculation, and recommend an evacuation zone. Tsunamis originating from the Cascadia and Alaska-Aleutian Islands subduction zones are expected to arrive within 1 and 4-5 h, respectively. In addition, earthquake source modeling suggests that several local sources could produce tsunamis that reach Alameda shores in 10-15 min. The Maximum Zone affects both Alameda and Bay Farm Island. Alameda Island has interior areas that could provide refuge, whereas a Maximum Zone evacuation for Bay Farm Island would require complete evacuation.

\subsection{Pedestrian evacuation potential}

Pedestrian travel times were mapped using an anisotropic, path distance, geospatial model implemented within ArcMap 10.2 software that focuses on the slope and land cover of an area to calculate the most efficient paths on foot to safety from every location in the Alameda evacuation zones (Wood and Schmidtlein 2012; Jones et al. 2014). Difficulty of traveling through each location is represented as a cost in terms of increased travel time. Anisotropy incorporates direction of travel, and path distance calculates distances and slopes between cells of varying elevations. Land cover and elevation-derived slope data are transformed into speed conservation values (SCVs) and represent the proportion of maximum travel speeds that are expected on areas with given conditions. Slope SCVs are based on Tobler's hiking function (Tobler 1993), and slopes were derived from 1-m resolution elevation data (A. Foxgrover, USGS Pacific Coastal Marine Science Center, personal communication, January 26, 2015).

Land cover SCVs are based on Soule and Goldman's (1972) energy cost terrain coefficients for certain land cover types, and geospatial land cover data were developed from a manual classification of the most recent Google Earth imagery and Google Maps street view, as well as supplemental geospatial data. A buildings footprint shapefile supplied by the City of Alameda (E. Smith, personal communication, November 6, 2014) was updated to reflect recent residential and commercial developments, as well as house demolitions on the Alameda NAS. Fences were digitized using the most recent Google Earth imagery and Google Maps street view with an emphasis on identifying very large fenced areas (e.g., golf courses or airports). Additional geospatial data to delineate land cover include wetland data from the National Wetland Inventory (US Fish and Wildlife Service 2015); water bodies from the National Hydrography Dataset (US Geological Survey 2015); and streets 
(Alameda County, CA 2014). The high residential density and numerous fences separating properties across Alameda suggest that pedestrian evacuations will be limited to paved surfaces (i.e., streets and parking lots). To limit pedestrian travel to paved surfaces, we used geospatial data delineating tax parcel boundaries (Alameda County, CA 2014) and related land use code data (Alameda County Data Sharing Initiative 2014) to identify residential parcels, which were then treated as pedestrian barriers in the model.

Travel cost surfaces that integrate land cover and slope variability are converted to maps of pedestrian travel times using a travel speed assumption of $1.22 \mathrm{~m} \mathrm{~s}^{-1}$ (Jones et al. 2014). This average walk assumption was chosen to reflect the mixed population of varying mobility, as well as the potential for slowing due to fatigue. Evacuation modeling also assumes instantaneous evacuations and does not incorporate evacuation delays.

\subsection{Population exposure}

Several datasets were assembled to estimate the number of people in the various Alameda evacuation zones. Residential estimates were created by distributing population counts in 2010 Census block data (US Census Bureau 2014a, b) to residential parcel centroids (Alameda County, CA 2014) using a spatial join and a ratio of point density per block within ArcMap 10.2. This method is not meant to associate an exact location of residents to parcels, but rather a topology to evenly apply census population within evacuation zone boundaries using tools available. Demographic factors, such as age, ethnicity, and tenancy, can amplify an individual's sensitivity to hazards and reduce their ability to respond (Cutter et al. 2003; Heinz Center 2002). For the residents in the evacuation zones, we inventoried demographic attributes available at the census block level and related to ethnicity (Hispanic or Latino), race (American Indian and Alaska Native, Asian, Black or African American, Native Hawaiian and other Pacific Islander, and White), age (individuals under five and over 65 years in age), gender with particular family structures (female-headed households with children under 18 years of age and no spouse present), and tenancy (group quarters and renter-occupied households).

Business characteristics were developed using a 2011 version of the Infogroup Employer Database (Infogroup 2011), which is a proprietary database that includes latitude and longitude coordinates, employee counts, and type based on the North American Industry Classification System (NAICS). We used NAICS codes to classify certain businesses as community-support businesses (e.g., banks or credit unions, civil or social organizations, gas stations, government offices, grocery stores, libraries, and religious organizations), dependent-care facilities (e.g., child services, elderly services, medical centers, and K-12 schools), critical facilities (e.g., fire stations, national security facilities, electrical facilities, and airline companies), and public venues (e.g., museums, overnight accommodations, and parks or other outdoor venues). In addition to spatial population data, we also acquired beach visitor data and marine live-aboard numbers (D. Cuoco, personal communication, November 20, 2014, and City of Alameda Planning and Building Department 2014). The census does not report residents who are live-aboard boats; therefore, manual identification and tabulation of docks was conducted using the most recent Google Earth imagery. Each population layer was overlaid on the evacuation zones and evacuation travel-time maps for each zone to estimate the number of individuals or facilities in terms of travel time to reach a boundary of each evacuation playbook zone.

Our population analysis focuses solely on Alameda and Bay Farm Islands. Although pedestrian evacuation modeling was completed for Coast Guard Island, we chose not to include it in subsequent population analyses, given the exclusively federal nature of the 
development. The island is home to several major US Coast Guard commands and publicly available information simply states that the island includes 700 housing units (United States Coast Guard 2016). Any further population analysis on our part would be speculative in nature, and ultimately, the Coast Guard would likely be implementing their own evacuation procedures separate from city officials.

\section{Results}

The four evacuation zones for the City of Alameda contain approximately 43,385 residents, which is $59 \%$ of the total population (Fig. 2). The evacuation zones also contain approximately 13,708 employees at 1036 businesses representing 67 and $44 \%$ of employees and businesses in the City of Alameda (Fig. 2). In addition to the people that live and work in the tsunami-evacuation zones, there are approximately 968 businesses likely to have a substantial number of local customers (e.g., retail), 430 dependent-care facilities (e.g., physician offices, schools, assisted living facilities), 69 public venues, and 14 critical facilities. In this section, we break down these numbers by evacuation zone and island to discuss the intra-community implications of recommending evacuations of the various zones on either island.

\subsection{Evacuation Zone 1}

Evacuation Zone 1 is recommended for tsunamis with expected water elevation (FASTER value) of 0-1 $\mathrm{m}$ and focuses on the evacuation of beaches, piers, and harbor docks. In our study area, it is confined to Alameda Island, except for one ferry terminal dock on Bay Farm Island. Zone 1 is descriptive and is not defined by geospatial boundaries; therefore, we discuss the number and distribution of docks and estimated population on these docks, instead of conducting a geospatial analyses. Based on a manual interpretation of satellite imagery, we identified 3240 small boat docks (i.e., not those intended for larger military,

(a)

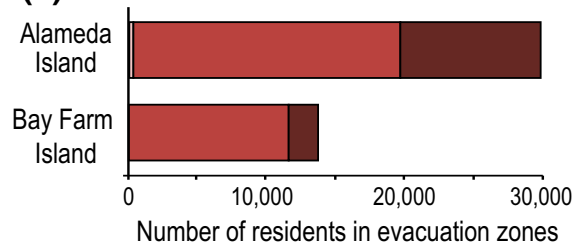

(b)

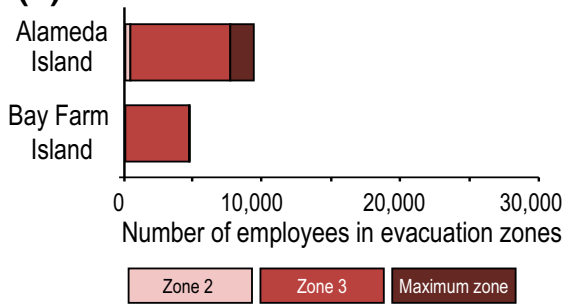

(c)

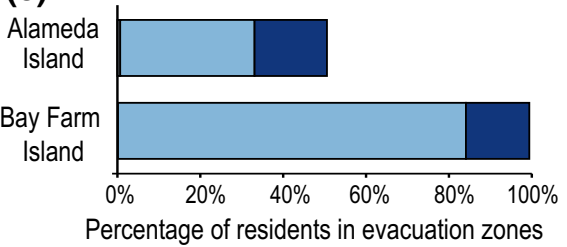

(d)

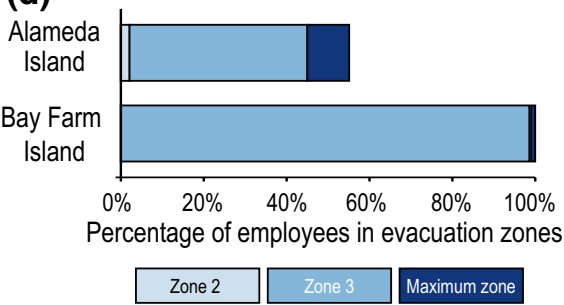

Fig. 2 Cumulative a numbers and $\mathbf{b}$ percentages of residents, and $\mathbf{c}$ numbers and $\mathbf{d}$ percentages of employees by evacuation playbook zone and island 
shipping, or coast guard vessels) in eight marinas and private docks along the Alameda coast (Table 1). According to regulations described by the City of Alameda Planning and Building Department (2014), approximately $10 \%$ of a marina's docks may be permitted as live aboard, which suggests that 340 docks (including 41 house boats) potentially are being used as homes (Table 1). Many marinas also allow temporary overnight stays on vessels that have overnight permits but do not keep accurate counts (B. de Lappe, Alameda Marina Harbor Master, personal communication, 2014).

Another area that would be evacuated during a Zone 1 evacuation is Robert W. Crown Memorial State Beach (Fig. 1), which is the only beach in the study area and attracts a substantial number of visitors. According to ongoing visitor attendance research conducted by the East Bay Regional Park District, average yearly attendance between 2004 and 2013 was approximately 484,223 people (D. Cuoco, personal communication, November 20, 2014). Assuming an equal distribution of visitors throughout the year, the beach receives approximately 1327 daily beach visitors on average. Actual daily attendance at this state beach is likely even greater on certain days because beach attendance is not uniform throughout the year. In a study of annual beach attendance of 75 southern California beaches in 2007, Dwight et al. (2007) conclude that $53 \%$ of all visits occurred in summer months and that $48 \%$ of all visits throughout the year occurred on weekends (27\% on Saturdays and $21 \%$ on Sundays). Therefore, after accounting for this variability in beach attendance and using these percentages, the number of visitors to Robert W. Crown Memorial State Beach is estimated to range from 288 visitors on a Tuesday in February to 6514 visitors on a Saturday in July. While Dwight et al. (2007) are based on southern California beach attendance and visitors may have been double counted, estimates are meant to provide some context as to the visitor fluctuations which could be impacted during a tsunami.

Table 1 Alameda Island boat dock and live-aboard estimates and approximate maximum estimated pedestrian travel times, by marina and evacuation playbook zone

\begin{tabular}{llllll}
\hline Marina & Live-aboard permits & Dock count & \multicolumn{2}{l}{$\begin{array}{l}\text { Maximum pedestrian travel time } \\
(\mathrm{min})\end{array}$} \\
\cline { 5 - 6 } & & & Zone 2 & Zone 3 & Maximum Zone \\
\hline Marina Village & 95 & & 4 & 18 & 25 \\
Grand Avenue Marina & 38 & 363 & 6 & 12 & 13 \\
Alameda Marina & 53 & 530 & 4 & 5 & 7 \\
Fortman Marina & 50 & 497 & 3 & 13 & 13 \\
Ballena Isle Marina & 50 & 500 & 4 & 18 & 18 \\
Aeolian Marina & 9 & 85 & 4 & 12 & 12 \\
Barnhill Marina & 41 & 61 & 3 & 12 & 28 \\
Mariner Square & 4 & 38 & 4 & 14 & 30 \\
Private docks & $\mathrm{n} / \mathrm{a}$ & $209^{\mathrm{c}}$ & $\mathrm{n} / \mathrm{a}$ & $\mathrm{n} / \mathrm{a}$ & $\mathrm{n} / \mathrm{a}$ \\
Total & 340 & 3240 & $\mathrm{n} / \mathrm{a}$ & $\mathrm{n} / \mathrm{a}$ & $\mathrm{n} / \mathrm{a}$ \\
Mean maximum travel time & $\mathrm{n} / \mathrm{a}$ & $\mathrm{n} / \mathrm{a}$ & 4 & 13 & 18.25
\end{tabular}

\footnotetext{
a Potential live-aboard permits, unverified

b 41 houseboats and 20 small boat docks

c No live aboards, docks are attached to homes
} 
Pedestrian evacuation modeling could not be conducted for the various beaches, piers, and harbor docks because Zone 1 is descriptive and is not delineated by geospatial boundaries. However, previous work on pedestrian evacuation modeling to evacuate docks before tsunami wave arrival in Alaskan coastal communities estimated clearance times of 10 min or less (Wood and Peters 2014). In our study area, estimated wave arrival times for all of the distant tsunami sources are on the order of hours, indicating that evacuations could be accomplished before wave arrival. Wave arrival times for local sources in Alameda are estimated to be 10-15 min (Wilson and Miller 2015), suggesting that successful evacuations from these events are likely during a Zone 1 evacuation unless the docks or piers are damaged during the associated earthquake.

\subsection{Evacuation Zone 2}

A Zone 2 evacuation could be recommended for a tsunami with water elevation of 1.0-1.5 $\mathrm{m}$. For the at-risk populations previously discussed in Zone 1 section, modeled clearance times out of Zone 2 range from 1 min for beachgoers at Robert W. Crown Memorial State Beach to $6 \mathrm{~min}$ for Grand Avenue Marina. Average minimum time to evacuate the various marinas is 4 min (Table 1). Eleven minutes of evacuation travel time is expected to evacuate from the end of the Alameda Ferry dock to safety outside of Zone 2 (Fig. 5).

In addition to transient populations on docks and beaches, we estimate that the Zone 2 evacuation area on Alameda Island contains approximately 204 residents and 350 employees (Fig. 2), as well as 22 community-support businesses, 4 public venues, 3 dependent-care facilities, and no critical facilities. Modeled clearance times out of this evacuation zone are estimated to be 1-14 min (Figs. 3a, 4), suggesting that successful evacuations are likely during a Zone 2 evacuation. The Zone 2 evacuation area on Bay Farm Island contains no residences or businesses (Fig. 2).

\subsection{Evacuation Zone 3}

A Zone 3 evacuation in Alameda is recommended for distant tsunamis with estimated arrival times of $4 \mathrm{~h}$ or more after an earthquake and expected water elevations of 1.5-2.5 m. Impacting both Alameda and Bay Farm Islands, the Zone 3 area adds approximately 29,843 residents to an evacuation, representing the majority of residents in the city's evacuation zones (69 \%), with 18,332 of them on Alameda Island (31\% of the island's population) and the other 11,511 residents on Bay Farm Island (85\% of the island) (Fig. 2).

A Zone 3 evacuation also adds 11,695 employees at 822 businesses to an evacuation, representing $85 \%$ of all employees in the various zones and $57 \%$ of the total workforce in the City of Alameda. Sixty percent of the 11,695 employees are on Alameda Island. Bay Farm Island has fewer employees in Zone 3 (4752 compared to 6943 on Alameda Island), but they represent $99 \%$ of the island's workforce (the remaining 29 employees are found in the Maximum Zone) (Fig. 2). Of the 822 businesses in the Zone 3 evacuation area, there are 272 community-support businesses, 116 dependent-care facilities, 42 public venues, and 6 critical facilities (Fig. 5).

The highest estimated evacuation travel times (60-74 min) were found where currently no populations live or work on Alameda Point and near runways of Oakland Airport. Areas where 45-59 min is likely needed to exit evacuation Zone 3 contain approximately 1234 Bay Farm Island employees, but no Alameda Island employees or residents on either island (Figs. 3b, 4). This portion of the Zone 3 evacuation area also contains 5 businesses likely to 

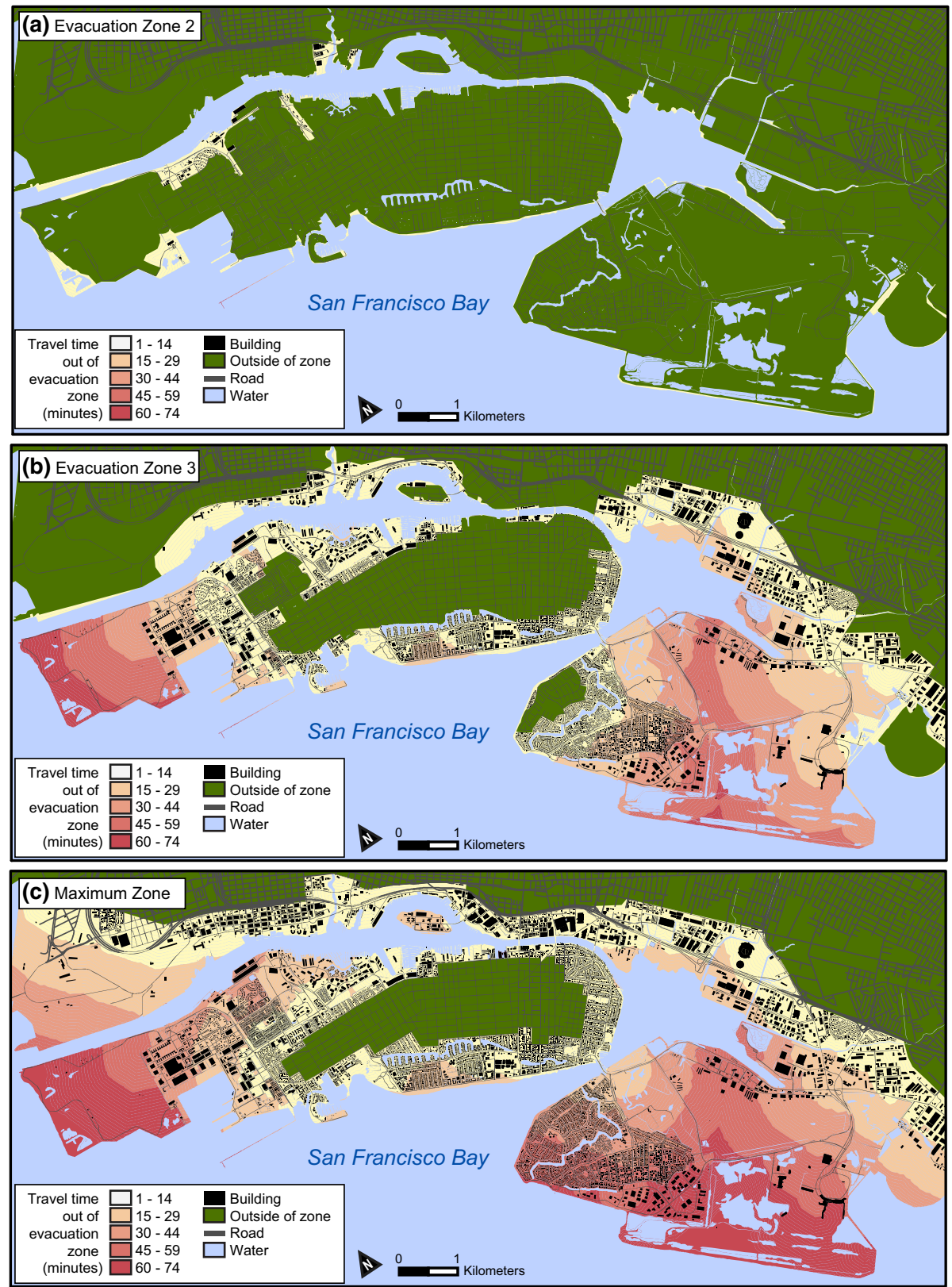

Fig. 3 Maps of modeled pedestrian travel times in the City of Alameda, assuming a travel speed of $1.22 \mathrm{~m} /$ s and evacuation playbook a Zone 2, b Zone 3 and $\mathbf{c}$ the Maximum Zone

have high customer counts, 2 dependent-care facilities, and 1 public venue. The majority of residents $(74 \%)$ and employees $(60 \%)$ in the Zone 3 evacuation area are at locations where modeled travel times are 1-14 min (Figs. 3b, 4). This trend also applies to the community-support businesses (209 out of 272 in the Zone 3 evacuation area), critical 


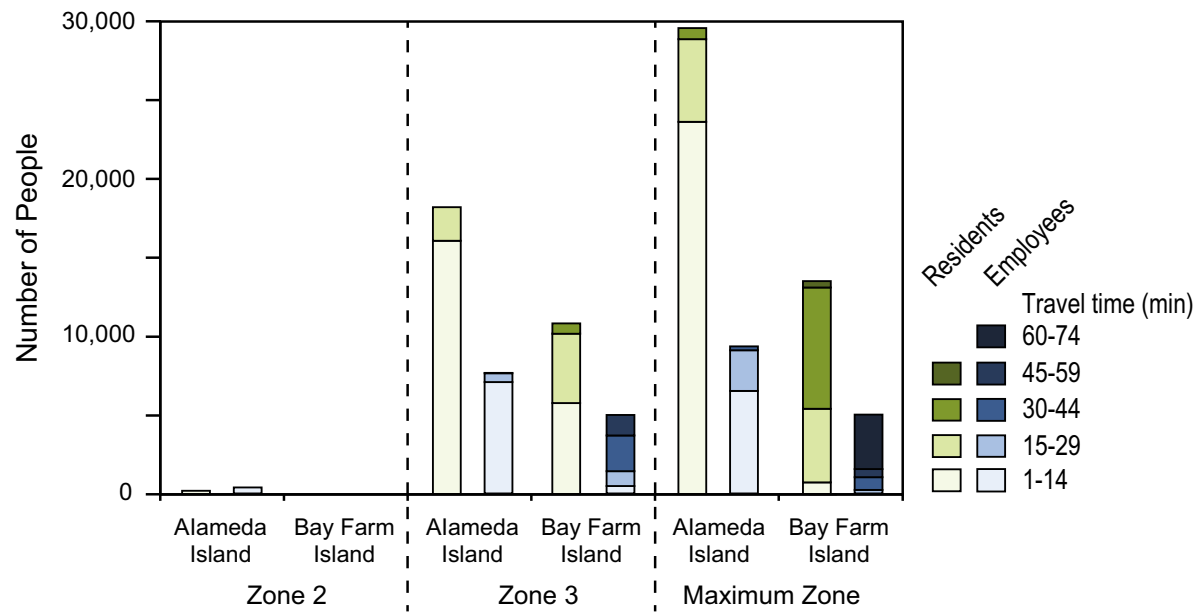

Fig. 4 Cumulative resident and employee numbers by travel times ( $\mathrm{min}$ ) to safety, by evacuation playbook zone and island

Fig. 5 Estimated travel times to safety for various evacuation zones on Alameda Island (AI) and Bay Farm Island (BFI) organized by business type
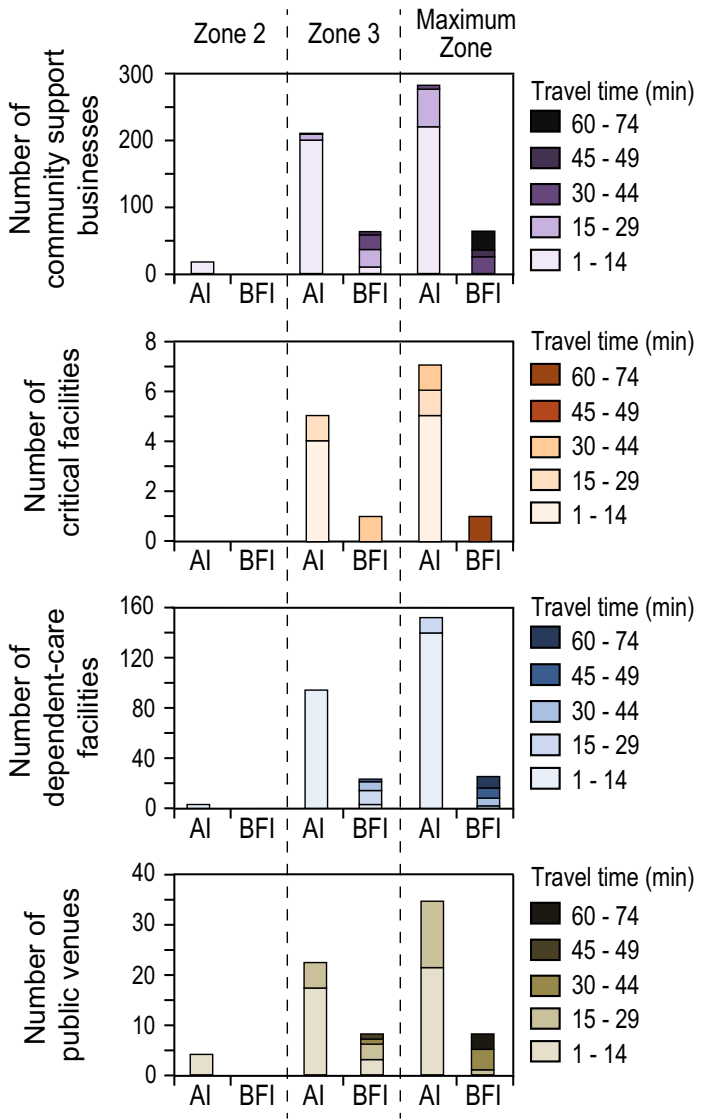
facilities (4 of 6), dependent-care facilities (96 of 116), and public venues (20 of 29), in which the majority of them are in areas where modeled travel times are less than $15 \mathrm{~min}$ (Figs. 3b, 5). Seven dependent-care facilities on Alameda Island in this portion of the Zone 3 evacuation area are affiliated with adult-assistance services and likely have residents who could require assistance evacuating and might need medical equipment and medication at a shelter during an evacuation (Wood et al. 2013a).

The typical estimated evacuation travel time from marinas along the shore out of the Zone 3 evacuation area is $13 \mathrm{~min}$, with the highest amount of time (18 $\mathrm{min}$ ) at Marina Village and Ballena Isle Marina (Table 1). As discussed earlier, the actual travel time may be longer for specific live-aboard residences given the time to exit a boat, as opposed to already being on a dock. The approximate travel time from the shoreline out of Zone 3 is $22 \mathrm{~min}$.

\subsection{Maximum evacuation zone}

Maximum Zone evacuations in Alameda will affect both islands (evacuates everyone from Bay Farm Island) and could be implemented for both large local and distant source events. Estimated wave arrival times are 10-15 min for local sources and $5 \mathrm{~h}$ or more for distant sources, except for a Cascadia subduction zone earthquake scenario where tsunami waves are expected within $1 \mathrm{~h}$ of ground shaking (Wilson and Miller 2015). The Maximum Zone evacuation area adds approximately 13,338 residents to an evacuation, with 11,249 of them on Alameda Island and the other 2089 residents on Bay Farm Island (Fig. 2). These increases represent 19 and $15 \%$ of the total population on Alameda Island and Bay Farm Island, respectively. The Maximum Zone also adds approximately 1634 Alameda Island employees (18\% of the island's workforce) and 29 Bay Farm Island employees (1\% of the island workforce) (Fig. 2). All of the additional 29 employees within the Maximum Zone on Bay Farm Island are affiliated with an elementary school. Other businesses with unique on-site populations that are added by a Maximum Zone evacuation include 50 community-support businesses (all on Alameda Island), 2 critical facilities (both on Alameda Island), 56 dependent-care facilities (54 of them on Alameda Island), and 8 public venues (all on Alameda Island).

Approximately $80 \%$ of the 23,792 Alameda Island residents in the maximum evacuation zone (i.e., encompassing all previous zones) are in areas where travel times to safety are 1-14 min, whereas only $5 \%$ of Bay Farm Island residents are in a similar situation (Fig. 4). The remaining Alameda Island residents are primarily in areas where travel times are 15-29 min (18\%) or 30-44 min (2\%). On Bay Farm Island, the majority of residents are in areas where evacuations could take 30-44 min (57\%), with smaller percentages at 15-29 (35\%), 1-14 $\min (5 \%)$, and 45-59 $\min (3 \%)$. For the entire city, this translates to $57 \%$ of all residents requiring less than $15 \mathrm{~min}$ to evacuate, $23 \%$ at $15-29 \mathrm{~min}, 20 \%$ at 30-44 min, and less than $1 \%$ at 45-59 min (Figs. 3c, 4). Areas with the highest travel times (60-74 $\mathrm{min}$ ) found on Alameda Island are on Alameda Point where currently no residents live or employees work but plans for developing this land are underway (Alameda Point Info 2016). The average travel time out of the maximum evacuation zone for all docks in the study area is $18 \mathrm{~min}$, with the highest at Mariner Square (30 min) (Table 1). Approximate travel time to safety for the state beach is $25 \mathrm{~min}$.

The distribution of employees is similar to the residents in that most of them are in areas that require 1-14 $\min$ (45\% of the city workforce) or 15-29 $\min$ (20\% of the workforce). However, there are 3311 employees $(24 \%)$ that are in areas of Bay Farm Island that may take 60-74 min to evacuate out of the Maximum Zone (Figs. 3c, 4). With regard to 
businesses with potentially unique on-site populations, there are 219 community-support businesses and 138 dependent-care facilities in areas on Alameda Island where 1-14 min is needed to evacuate the maximum evacuation zone. Areas requiring 15-29 min to evacuate include 56 community-support businesses, 1 critical facility, 12 dependent-care facilities (including 1 additional adult-assistance facility), and 13 public venues. One critical facility (a fire-protection training facility) is an area where 30-44 min is needed to evacuate (Figs. 3c, 5).

On Bay Farm Island, evacuation travel times for all businesses and facilities increase for a Maximum Zone evacuation due to no remaining safe area on the island. For example, travel time to safety for the 1 critical facility (an airline-related business) on Bay Farm Island increases to 60-74 min. The only 2 additional facilities on Bay Farm Island that could be impacted when transitioning from Zone 3 to the Maximum Zone are dependentcare facilities (an elementary school and a day-care center) and are located in an area where travel time to safety is estimated at 30-44 min (Figs. 3c, 5).

\subsection{Demographic characteristics of residential evacuees}

Information on demographic characteristics of residents who live in the tsunami-evacuation zones can help emergency managers in their effort to implement realistic evacuation procedures. Demographic data are available only for residential counts in US Census data and not for employees, customers, or tourists; therefore, we limit our discussion here to characteristics of residents in delineated evacuation zones. Because of the magnitude of demographic characteristics found at the block level, we also limit our discussion to variations in demographic attributes related to age, ethnicity, and tenancy that vary plus or minus $5 \%$ of the City of Alameda average. As discussed earlier, the number of residents in evacuation Zone 2 on Alameda Island is relatively low (204) (Fig. 2). Comparing demographic characteristics of residents in this zone to all residents in the City of Alameda, the at-risk population in Zone 2 has a slightly higher percentage of individuals that identify themselves as Hispanic or Latino, White, Black or African American, and female-headed households with children and no husband present (Fig. 6). Zone 2 also has a substantially higher percentage of residents in renter-occupied households and a substantially lower percentage of Asian Americans. As more residents of Alameda Island are asked to evacuate in Zone 3 and the Maximum Zone, the demographic characteristics of the evacuee population becomes similar to the city wide percentages. This is not the case, however, on Bay Farm Island, where the evacuee populations in Zone 3 and the Maximum Zone have higher percentages of residents that identify themselves as Asian, but lower percentages of Hispanic or Latino, White, Black or African American, female-headed households with children and no husband present, and renter-occupied households (Fig. 6).

\section{Discussion}

Tsunami-evacuation planning is a difficult task for coastal jurisdiction emergency managers due to the range of potential tsunami sources, tidal influences, wave arrival times, and extents of inundation. Although evacuation zones based on maximum inundation from a variety of sources can help identify the highest number of individuals who could be directly impacted by any tsunami, these zones may also lead to over-evacuations, extended business disruption, and public distrust in evacuation practices for lower level, more 


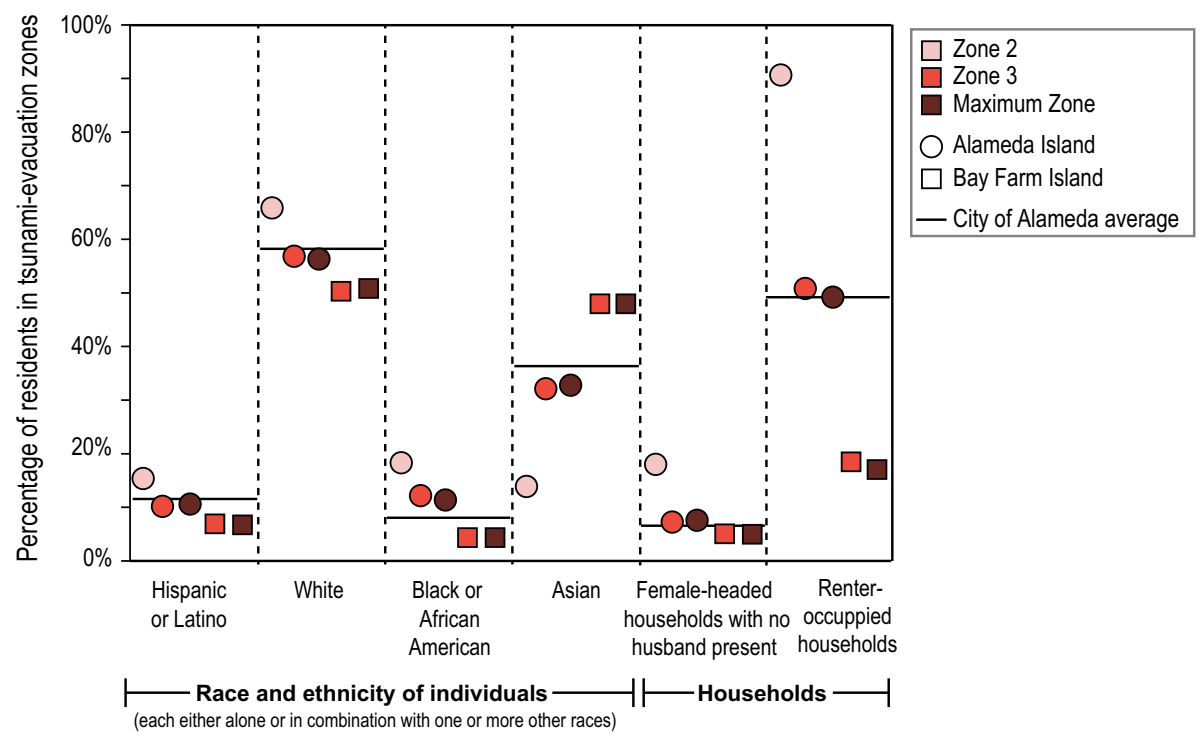

Fig. 6 Demographic characteristics of residents in the various evacuation zones, showing only demographic percentages that varied more than $5 \%$ of city averages

frequently experienced events. In this paper, we explored the potential evacuation implications of using multiple tsunami-evacuation zones (playbooks) and focusing on the City of Alameda, which recently has developed a series of evacuation zones based on the severity of an impending tsunami. In this section, we discuss the implications of our results on evacuation planning and the challenges faced by emergency managers when they must act in the absence of perfect information, the potential strategies to mitigate these challenges, and suggested future research based on our results.

Results suggest substantial variations in the number and type of evacuees in the various evacuation zones. Evacuation Zone 1 in our study area covers a state beach, 8 marinas, 2 ferry terminals, an aircraft carrier museum, and numerous private docks; therefore, evacuees are primarily residents who are live-aboard boats, beachgoers, tourists, and boating enthusiasts. These populations likely fluctuate (daily, weekly, and seasonally) and may include people who do not normally live in tsunami-prone areas. As such, they may not have high awareness of tsunami hazards or of what to do during an evacuation. Daytime tsunamis resulting in an evacuation of Zone 1 will likely have greater impacts than nighttime events, given the tourism-based populations in this zone. The one exception is people living on boats in marinas. Given the transient nature of at-risk individuals in evacuation Zone 1, education and outreach strategies could include signage; kiosks with evacuation guidance; protocols for the maritime community (Wilson et al. 2016), dock lease holders, or live-aboard residents; and evacuation exercises. Developing Emergency Operations Plans incorporating tsunami-evacuation planning, as well as testing and implementing them when needed, will serve as the foundation for evacuating an educated populace. Modeling results suggest that populations at the beach and docks will likely have more than adequate time to reach safety before the first wave in a tsunami arrives; however, this is based on the assumption that at-risk individuals initiate self-protective actions quickly and without hesitation. 
If emergency managers extend an evacuation to include Zone 2, our results indicate a low number of additional residents (204) and employees (350) will be added to those from Zone 1 on Alameda Island and no additional people on Bay Farm Island (Fig. 2). Zone 2 also adds 22 retail businesses, 4 public venues, a medical clinic, and 2 child-care centers (Fig. 5) to an evacuation, and while these sites will contribute to the number of evacuees, their potential loss would not impact the execution of emergency response efforts like the loss of a police or fire station could. Unlike transient populations in Zone 1, resident and business addresses within Zone 2 could be targeted for tsunami awareness and evacuation outreach. Estimated travel times indicate evacuees should have sufficient time to travel outside of Zone 2 on foot before the arrival of the first tsunami wave. Demographic analysis of individuals in Zone 2 suggests that evacuation-education efforts should be developed and implemented in ways to best reach the relatively high concentration of renters (Fig. 6).

The largest increase in residential and employee evacuee populations occurs with the decision to call a Zone 3 evacuation. Our results indicate that a Zone 3 evacuation would add tens of thousands of people beyond that already involved in either a Zones 1 or 2 evacuation, representing the majority of the at-risk population in our study area. As was the case with businesses in Zone 2, none of the 822 businesses or facilities in Zone 3 are critical facilities such as police or fire stations that, if lost, would impact an evacuation (Fig. 5). There are, however, many businesses and offices that when closed for an evacuation could greatly impact those businesses and the quality of life of non-evacuating residents, including banks (4), government offices (15), libraries (2), markets (5), K-12 schools (9), child day-care centers (6), medical offices (92), and adult-residential-care centers (6). The various dependent-care facilities (e.g., schools, child day-care centers, and adult-residential-care centers) in Zone 3 suggest that evacuating some at-risk individuals may be more difficult than the general public. Another potential issue that complicates an evacuation is parents entering the evacuation zone to retrieve their children from schools and day-care centers, as well as relatives or friends picking up residents who live in adultresidential-care centers. One mitigating factor is that potential sources associated with a Zone 3 evacuation are likely distant earthquakes only and expected tsunami arrival times of $4 \mathrm{~h}$ or more should provide sufficient time to implement a successful evacuation before wave arrival. Given the long wave arrival time and relatively shorter evacuation-clearance times (Fig. 3b), the challenge for emergency managers during a Zone 3 evacuation may be less of the threat of life loss but more of how to mobilize, guide, and potentially provide sheltering services for the large populations expected to evacuate. However, areas of Zone 3 would be expected to evacuate during a Maximum Zone evacuation which may include local and regional sources where evacuation-clearance times may be relatively short.

A related aspect of guiding at-risk individuals to safety is the conditions at identified safe areas. While at-risk individuals in a Zone 3 evacuation on Alameda Island can be dispersed to a large area of the island's interior, individuals on Bay Farm Island are theoretically moving to a substantially smaller area on the northwest side of the island (Fig. 3b). Given the area of this predicted safe zone and the number of at-risk individuals on the island, the resulting population density during an evacuation would be approximately 22,192 persons per sq $\mathrm{km}$, which is over ten times the pre-tsunami population density on Bay Farm (2091 persons per sq km) and over three times the population density of nearby San Francisco (approximately 6632 persons per sq km) (US Census Bureau 2015). Therefore, follow-up studies on alternative evacuation planning or the ability for these safe areas to accommodate such high numbers of evacuees, including consideration of appropriate and adequately engineered vertical evacuation structures, may be warranted. 
Implementing an evacuation to the Maximum Zone adds fewer people to the evacuation than a Zones 2-3 transition (13,338 residents, which is $44 \%$ of the Zone 3 addition). The number of businesses in the Maximum Zone and not in smaller zones is also less (150 compared to 822) but could have a similar effect on business disruption or quality of life (e.g., retail, medical offices, banks, markets, schools) (Fig. 5). One new complication to a Maximum Zone evacuation is the addition of a medical center on Alameda Island, which may have difficulty evacuating all patients in a timely fashion (Wood et al. 2013b). Plans for developing Alameda Point could add another complication to a Maximum Zone evacuation by potentially increasing the number of residents and employees where the longest estimated travel times to safety were found. Consideration of the tsunamievacuation playbook zones by planners of new developments in Alameda could be useful for decision making.

Although a Maximum Zone evacuation may not introduce as many new evacuees as Zone 3 could, it does introduce new issues of clearance time, evacuee destinations, and public perception of the threat. A comparison of wave arrival times for local sources associated with the Maximum Zone (Table 1), maps of modeled pedestrian clearance time (Fig. 2), and graphs of population exposure as a function of travel time to safety (Figs. 4, 5) suggest that there are thousands of residents and employees, as well as hundreds of businesses, in areas where people would not have enough time to evacuate the Maximum Zone before wave arrival. Table 1 summarizes several local-source scenarios with estimated 10- to 15-min wave arrivals and a Cascadia, full-rupture scenario (M9.0) with an estimated 1-h wave arrival, but evacuation travel times are greater than that in many parts of the study area (Fig. 3).

In reality, the evacuation situation is not as dire as it may seem for many at-risk individuals in these scenarios and it highlights a challenge of emergency managers related to communicating short arrival tsunami threats to the public. Recommendations for evacuating smaller zones in Alameda (e.g., Zones 1-3) are based solely on distant source events with wave arrival times of $4 \mathrm{~h}$ or more because emergency managers likely would have sufficient time to determine the extent of an imminent tsunami threat and communicate evacuation guidance to at-risk populations. Evacuation of the Maximum Zone, however, may be implemented by a mix of distant events with wave arrival times ranging from 1 to $5 \mathrm{~h}$ and local sources with arrival times of 10-15 min. In some cases, the decision to implement a Maximum Zone evacuation for a distant source reflects high expected water elevations (e.g., Alaska-Aleutian Island source scenarios). Modeling results suggest that everyone in areas of the Maximum Zone would have sufficient time to evacuate in the $5 \mathrm{~h}$ before expected wave arrival from these sources, as long as delays and complications do not arise.

Some local and regional tsunami source scenarios associated with a Maximum Zone have expected water elevation values that are more reflective of a Zone 1 evacuation (e.g., 0-1 m expected water elevation) or Zone 2 evacuation (e.g., 1.0-1.5 m expected water elevation) (Wilson and Miller 2015). However, wave arrival times are on the order of 10-15 min for the various large local-source events and $1 \mathrm{~h}$ for a large Cascadia earthquake. It may be difficult, if not impossible, for tsunami modelers to thoroughly assess an impending tsunami and confidently communicate playbook parameters (including FASTER and a zone recommendation) to local emergency managers in the limited time before waves arrive. These short arrival times have led local and state emergency managers to be risk averse and therefore recommend Maximum Zone evacuations for these events as an attempt to move evacuees as far from the shoreline as possible, even though water elevation is unlikely to reach the full extent of the Maximum Zone. Recognizing this 
distinction, one can see in Fig. $3 b$ that all areas in evacuation Zone 2 can be evacuated in less than $15 \mathrm{~min}$. Therefore, at-risk individuals will likely have sufficient time to evacuate out of the truly high risk areas of Zone 2 for these scenarios, even though individuals may not feel it is possible given the extent of the Maximum Zone that may be communicated in outreach. Additionally, if emergency managers felt confident in calling a Zone 2 evacuation for a local or Cascadia sourced tsunami, no one would be asked to leave Bay Farm Island.

Emergency managers therefore have to wrestle with competing evacuation challenges. With the current procedures of evacuating the Maximum Zone for local or Cascadia sources, emergency managers run the risk over-evacuating thousands of people due to insufficient time to validate attributes of an impending tsunami in order to be confident in communicating evacuation of smaller zones (e.g., Zones 1-3). If they attempted to recommend evacuation orders for smaller zones for these same scenarios in outreach efforts, they run the risk of under-evacuating thousands of people because at-risk individuals may wait for evacuation orders, significantly reducing the amount of available time for an evacuation. An appropriate compromise may be in retaining the recommendation to evacuate to the Maximum Zone, but with the understanding that lower water elevations may be expected for these local sources. In the future, emergency managers may be able to modify evacuation procedures for these short arrival events as communication technology and dynamic inundation modeling continue to improve. In the short term, emergency managers may have to contend with public perceptions of over-evacuations for certain types of tsunamis. More research exploring the willingness of the public to learn tsunami information or participate in outreach efforts, as well as understanding past public reactions to over-evacuation, is warranted.

One challenge when implementing a Maximum Zone evacuation for Bay Farm Island is that at-risk individuals will be asked to evacuate completely off of the island and may choose to travel east out of the City of Alameda to the Oakland mainland (Figs. 1, 3c). This raises the issue of having to coordinate evacuation policies and protocols among neighboring communities. Although evacuation planning is typically handled by internal community planning, our results indicate that evacuees traveling from the Maximum Zone on Bay Farm Island may need to seek safety within neighboring jurisdictions. The pre-tsunami coordination of evacuation procedures, assembly areas, and evacuee services between jurisdictions could minimize any potential confusion during an event.

Additional challenges in implementing a Maximum Zone evacuation on Bay Farm Island are the long distances and large fenced areas (e.g., golf course and Oakland airport in Fig. 1) along the primary routes. Two evacuation scenarios could result from evacuees thinking safety is too far in neighboring Oakland. Many Bay Farm Island evacuees may try and evacuate to Alameda Island across the one connected bridge (Fig. 1), instead of traveling east to Oakland. If all at-risk residents on Bay Farm Island did this and joined the Alameda Island evacuees and existing residents in this area, the population density of that area could reach approximately 13,745 persons per square $\mathrm{km}$, which is two times the population density of nearby San Francisco. These increases in population density represent challenges for emergency managers when deciding whether to keep their evacuation contained within their city limits or to partner with surrounding jurisdictions and potentially relieve some of the density.

Another evacuation scenario for Bay Farm Island residents not wishing to walk the long distance to nearby Oakland is the use of vehicles during the evacuation. The relatively long expected arrival times for the distant tsunami sources ( 1 or more hours) may lead at-risk individuals to believe that there is enough time to prepare and evacuate by vehicle. It can 
be counterintuitive to think that traveling by foot could move at-risk populations out of tsunami zones faster than vehicles, but limited egress points for vehicles off of Bay Farm Island suggest that congestion could disrupt the flow of evacuating vehicles. Traffic simulation modeling of Bay Farm Island populations traveling off the island in vehicles may be warranted to understand whether this method of evacuation could be successful during a tsunami event and if not, the communication strategies to discourage vehicular evacuations.

\section{Conclusions}

The objective of this paper was to examine the population and evacuation implications for multi-zone evacuation planning summarized in tsunami-evacuation playbooks for coastal communities along the California coast. We calculated population magnitudes and pedestrian travel times to safety for the various evacuation zones in Alameda, California, to help emergency managers better understand the evacuation context of each zone. Based on our case study of Alameda, we reach several conclusions that bear on tsunami-evacuation planning in coastal communities.

- Evacuation modeling suggests that at-risk populations should have sufficient time to reach safety before estimated wave arrival for each evacuation zone; however, the magnitude and types of evacuees vary from beach visitors and boaters in Zone 1 to over 43,000 mixed populations in the Maximum Zone.

- Implementing the FASTER approach and playbook-type evacuation plans for distant source events (greater than $4 \mathrm{~h}$ travel time) may provide safe and consistent secondary options for emergency managers that are still conservative but better match the amount of potential flooding considering the tsunami and tidal conditions. This approach could also greatly reduce the number of evacuees below a Maximum Zone evacuation, especially between Zone 2 (204 residents) and Zone 3 (29,843 residents) evacuations in Alameda.

- None of the 1306 business and offices in the various evacuation zones include critical facilities that, if lost, would influence the ability of the city to implement evacuations, but do include businesses and offices that could suffer disruptions and greatly impact the quality of life within communities, including banks, government offices, libraries, markets, K-12 schools, child day-care centers, medical offices, and adult-residentialcare centers.

- Identified safe areas may not be able to accommodate the expected evacuee population, as results suggest very high population densities in these areas after an evacuation. Adequate refuge exists at the center of Alameda Island.

- Evacuees, especially for Bay Farm Island, may need to evacuate and find shelter in neighboring jurisdictions, which highlights the need for multi-jurisdictional evacuation planning coordination.

- Implementing a Maximum Zone evacuation is currently recommended by the Alameda Tsunami Evacuation Playbook for local and Cascadia tsunami sources given the limited amount of available time to assess tsunami attributes and communicate recommendations for smaller zones. This approach, however, may also result in an overevacuation and the public may perceive successful evacuations as not possible given the longer pedestrian travel times required to completely evacuate the Maximum Zone. 
This issue could also result in individuals thinking that car-based evacuations are the solution; yet, traffic congestion could hamper evacuations.

Acknowledgments This study was supported by the US Geological Survey (USGS) Land Change Science Program and the Science Application for Risk Reduction (SAFRR) project. We thank Sharon Oliver, Captain of the City of Alameda Fire Department, for helping to frame this research and for her insight on evacuation planning and challenges in Alameda. We also thank Mara Tongue of the USGS, Chris Gregg of East Tennessee State University, and anonymous reviewers for their reviews of earlier versions of the article. Any use of trade, product, or firm names is for descriptive purposes only and does not imply endorsement by the US Government.

Open Access This article is distributed under the terms of the Creative Commons Attribution 4.0 International License (http://creativecommons.org/licenses/by/4.0/), which permits unrestricted use, distribution, and reproduction in any medium, provided you give appropriate credit to the original author(s) and the source, provide a link to the Creative Commons license, and indicate if changes were made.

\section{References}

Alameda County, CA (2014) Geospatial data files website. http://www.acgov.org/government/geospatial. htm. Accessed 27 Oct 2014

Alameda County Data Sharing Initiative (2014) Alameda County data sharing website. http://data.acgov. org/Housing-and-Development/Assessor-s-Office-Secured-Tax-Roll-2013-2014/75yc-v7vd. Accessed 27 Oct 2014

Alameda Point Info (2016) Alameda point info website. http://alamedapointinfo.com/. Accessed 26 Feb 2016

Bernard E (2005) The US National Tsunami Hazard Mitigation Program: a successful state-federal partnership. Nat Hazards 35:5-24

Butler R (2014) Great Aleutian tsunamis: University of Hawaii at Manoa, School of Ocean and Earth Science and Technology. http://www.higp.hawaii.edu/reports/2014/. Accessed 2 April 2015

California Department of Conservation (2015) Official tsunami inundation maps. http://www.conservation. ca.gov/cgs/geologic_hazards/Tsunami/Inundation_Maps/Pages/Index.aspx. Accessed 18 Feb 2016

City of Alameda Planning and Building Department (2014) Draft general plan housing element 2007-2014. http://alamedaca.gov/sites/default/files/document-files/files-inserted/housing-element.pdf. Accessed 19 Nov 2014

Cutter S, Boruff B, Shirley W (2003) Social vulnerability to environmental hazards. Soc Sci Q 4(1):242-261

Dwight R, Brinks M, Sharavana Kumar G, Semenza J (2007) Beach attendance and bathing rates for southern California beaches. Ocean Coast Manag 50(10):847-858

East Bay Regional Park District (2014) Robert W. Crown Memorial State Beach website. http://www. ebparks.org/parks/crown_beach\#activities. Accessed 30 Nov 2014

Heinz Center (2002) Human links to coastal disasters. The H. John Heinz III Center for Science, Economics and the Environment, Washington, DC

Infogroup (2011) Employer database: Infogroup online dataset. http://referenceusagov.com/Static/Home. Accessed 27 Oct 2014

Jones JM, Ng P, Wood NJ (2014) The pedestrian evacuation analyst-geographic information systems software for modeling hazard evacuation potential. U.S. Geological Survey Techniques and Methods, book 11, chap. C9. Retrieved from doi:10.3133/tm11C9. ISSN: 2328-7055

Ministry of Civil Defence and Emergency Management (2008) Tsunami evacuation zones, director's guideline for civil defence emergency management groups. [DGL 08/08]. Wellington, New Zealand

National Research Council (2011) Tsunami warning and preparedness - an assessment of the U.S. Tsunami Program and the nation's preparedness efforts, Committee on the Review of the Tsunami Warning and Forecast System and Overview of the Nation's Tsunami Preparedness, Ocean Studies Board, National Research Council

Priest GR, Stimely LL, Wood NJ, Madin IP, Watzig RJ (2016) Beat-the-wave evacuation mapping for tsunami hazards in Seaside, Oregon, USA. Nat Hazards 80(2):1031-1056

Soule R, Goldman R (1972) Terrain coefficients for energy cost prediction. J Appl Physiol 32:706-708 
Tobler W (1993) Three presentations on geographical analysis and modeling-non-isotropic geographic modeling. Speculations on the geometry of geography; and global spatial analysis. UCSB. National Center for Geographic Information and Analysis Technical Report 93-1. http://www.ncgia.ucsb.edu/ Publications/Tech_Reports/93/93-1.PDF. Accessed 19 July 2010

U.S. Fish and Wildlife Service (2015) National Wetlands Inventory website. http://www.fws.gov/wetlands/ Data/State-Downloads.html. Accessed 20 Jan 2015

U.S. Census Bureau (2014a) American FactFinder U.S. Census Bureau web site. http://factfinder2.census. gov/faces/nav/jsf/pages/index.xhtml. Accessed 27 Oct 2014

U.S. Census Bureau (2014b) 2010 TIGER/Line ${ }^{\circledR}$ Shapefiles: U.S. Census Bureau web site. http://www. census.gov/cgi-bin/geo/shapefiles2010/main/. Accessed 27 Oct 2014

U.S. Census Bureau (2015) City of San Francisco and Los Angeles QuickFacts from the US Census Bureau. http://www.census.gov/quickfacts/table/POP060210/0644000,0667000. Accessed 20 Jan 2015

U.S. Coast Guar (2016) Welcome to Coast Guard Island Alameda. http://www.uscg.mil/baseAlameda/. Accessed 18 Feb 2016

U.S. Geological Survey (2015) National hydrography dataset download website. http://factfinder2.census. gov/faces/nav/jsf/pages/index.xhtml. Accessed 20 Jan 2015

Walsh T, Caruthers C, Heinitz A, Myers E III, Baptista A, Erdakos G, Kamphaus R (2000) Tsunami hazard map of the southern Washington coast-modeled tsunami inundation from a Cascadia subduction zone earthquake. Washington Department of Natural Resources Division of Geology and Earth Resources Geologic Map GM-49

Wilson RI, Miller KM (2014) Tsunami emergency response playbooks and FASTER tsunami height calculation: background information and guidance for use. California Geological Survey Special Report 236

Wilson RI, Miller KM (2015) California tsunami evacuation playbook city of Alameda-Alameda County. California Tsunami Evacuation Playbook No. 2014-Alam-01, unpublished report, Sacramento CA; associated with: tsunami emergency response playbooks and FASTER tsunami height calculation: background information and guidance for use. California Geological Survey Special Report 236

Wilson RI, Barberopoulou A, Borrero JC, Bryant WA, Dengler LA, Goltz JD, Legg MR, McGuire T, Miller KM, Real CR, Synolakis CE (2010) Development of new databases for tsunami hazard analysis in California. In: Lee WHK, Kirby SH, Diggles MF (eds) Compilers, 2010, program and abstracts of the second tsunami source workshop; July 19-20, 2010: U.S. Geological Survey Open-File Report 2010-1152

Wilson RI, Lynette P, Admire A, Ayca A, Curtis E, Dengler L, Hornick M, Nicolini T, Peterson D (2016) Maritime tsunami response playbooks: background information and guidance for response and hazard mitigation use. California Geological Survey Special Report 241

Wood NJ, Peters J (2014) Variations in population vulnerability to tectonic and landslide-related tsunami hazards in Alaska. Nat Hazards 75(2):1811-1831

Wood NJ, Schmidtlein MC (2012) Anisotropic path modeling to assess pedestrian-evacuation potential from Cascadia-related tsunamis in the US Pacific Northwest. Nat Hazards 62(2):275-300

Wood N, Ratliff J, Peters J (2013a) Community exposure to tsunami hazards in California, U.S. Geological Survey Scientific Investigations Report 2012-5222

Wood N, Ratliff J, Peters J, Shoaf K (2013b) Population vulnerability and evacuation challenges in California for the SAFRR tsunami scenario, chap. I. In: Ross SL, Jones LM (eds) The SAFRR (Science Application for Risk Reduction) tsunami scenario, U.S. Geological Survey Open-File Report 2013-1170 